\title{
Study on the Bottleneck of Urban Rail Transit Capacity Based on Network
}

\author{
Sudan $^{1, a}$ \\ ${ }^{1}$ School of mechanical engineering, Ningxia University, Yinchuan,Ningxia,750021 China \\ a423408618@qq.com
}

Keywords: urban rail transit; transport capacity; bottleneck; passenger flow assignment

\begin{abstract}
With the continuous progress of the urban rail transit network, the passenger flow records of the urban rail transit are constantly refreshed under the double stimulation of the network effect and the fare. As the passenger flow rapidly increases, various problems of incompatibility on the related facilities or equipment of the urban rail transit have appeared at the same time, which, require the revolution of the bottleneck of the transport capacity as soon as possible. Thus, the paper does a systematic study on the bottleneck of urban rail transit capacity.
\end{abstract}

\section{Introduction}

The continuous formation of urban rail transit network, the expand of scale of the road network and the continuous upgrading of road network structure require better sharing of resources, centralized command and intelligent management under the networking environment. To achieve resource sharing and integrated utilization within the whole network, the problems of bottlenecks identify and digest of road network capacity shall be solved to develop the overall capacity and integrated benefits of urban rail transit network system.

\section{Composition of Urban Rail Transit Network System}

Urban rail transit system is a complex system including the equipment (vehicles) and a variety of fixed equipment (lines, stations, vehicle bases, control systems, power supply and environmental control equipment, etc.).

\section{Line}

(1) Type of line. In accordance with the role of line in the operation, urban rail transit lines can be divided into three categories of main line, the car line and auxiliary line. Main lines drive the passenger train. Car lines are used for the vehicle cleaning, screening, grouping, parking, maintenance and commissioning within the vehicle depot. Auxiliary lines do not carry passenger generally.

(2) Main technical standards of line. The main technical standards of main line and auxiliary line of urban rail transit are shown in table 2.1. According to the long term of one-way transportation capacity in peak hours, the large-volume urban rail transit is usually adopted with Vehicle A or Vehicle B and middle-volume urban rail transit is generally adopted with Vehicle L or Vehicle C. 
Table 1 Main technical standards of main and auxiliary line

\begin{tabular}{|c|c|c|c|c|}
\hline Basic Model & $\begin{array}{c}\text { Type of } \\
\text { Line }\end{array}$ & Vehicle A & Vehicle B & Vehicle C \\
\hline $\begin{array}{c}\text { Minimum Radius } \\
\text { of Curve(m) }\end{array}$ & Main line & $\begin{array}{c}300 \sim 350 \\
150-250\end{array}$ & $\begin{array}{c}250 \sim 300 \\
150 \sim 200\end{array}$ & $\begin{array}{c}50-100 \\
25 \sim 80\end{array}$ \\
\hline Maxiliary & Main line & $30 \sim 35$ & $30 \sim 35$ & 60 \\
Slope(\%) & Auxiliary line & 40 & 40 & 60 \\
\hline Rail Weight(kg / & Main line & $\geqslant 60$ & $50-60$ & 50 \\
m) & Auxiliary line & $\geqslant 50$ & $\geqslant 50$ & 50 \\
\hline
\end{tabular}

\section{Station}

The urban rail transit station is the place where the passengers get on or off, the place of transfer, and the place where the train arrives, passes, returns or temporarily stops.

(1) Classification of station. The station can be classified in different ways. The station can be divided into terminal station, intermediate station, reverse station and transfer station according to different functions of operation; centralized control station and non-centralized control station according to station control function; island platform, side platform and complex platform in accordance with the form of the platform; different levels of the station according to the volume of the traffic; attended management and unattended management station in accordance with the management of person; and underground stations, elevated station and ground station in accordance with the line laying.

(2) Basic constitution of station: the station is generally composed of entrance and exit, station hall, platform and production plant, with the connection of channel, staircase, escalator, entrance, the station hall and the platform.

(3) Vehicle. Vehicle is the carrier of passengers. Urban rail transit vehicles shall ensure not only the safety, fast and large capacity of functions, but also a good and comfortable travel environment.

Vehicle can also be divided in different ways. China's Vehicle A, Vehicle B, Vehicle C and Vehicle L, as shown in table 2.2; can be divided into motor vehicles and trailers in accordance with different installations of traction power. Motor vehicle is a vehicle with its own powered installation. Trailer is a vehicle without its powered installation.

Table2 Main technical specification and performance of four basic models

\begin{tabular}{|c|c|c|c|c|}
\hline Model & Vehicle A & Vehicle B & Vehicle C & Vehicle L \\
\hline Width of Vehicle & 3000 & 2800 & 2600 & 2800 \\
\hline Vehicle Capacity & 310 & 230 & 210 & 100 \\
\hline $\begin{array}{c}\text { Max Speed of Train(kin / } \\
\text { h) }\end{array}$ & 80 & 80 & 80 & 1 \\
\hline $\begin{array}{c}\text { Starting Acceleration(m / } \\
\text { s2) }\end{array}$ & 1.0 & 1 & 1.0 & 1 \\
\hline $\begin{array}{c}\text { General Braking } \\
\text { Deceleration (nl / s2) }\end{array}$ & 1.0 & 1.3 & 1.3 & 1.3 \\
\hline $\begin{array}{c}\text { Emergency Braking } \\
\text { Deceleration(m / s2) }\end{array}$ & 1.3 & DCl500 & DCl500 & DCl500 \\
\hline $\begin{array}{c}\text { Voltage of Power } \\
\text { Network(v) }\end{array}$ & DCl500 & & & \\
\hline
\end{tabular}

\section{Vehicle Base}

The vehicle base is the general term for the depot and the parking lot. The vehicle depot is the place where the vehicle is used, parked, overhauled, and daily maintenance and repair operations of the technical inspection, vehicle cleaning and washing and so forth. The functions of parking lot are the same as the depot in addition to the regular vehicle maintenance. 


\section{The Solution of the Bottleneck of Urban Rail Transit Capacity Based on Network}

1. Work out a good equipment renovation scheme

(1) Build two-lane or four lines: owing to the immovability of the location of urban housing and public buildings, the corresponding traffic passenger is not easy to be divided by other rail transit lines Shunt once the gathering function of commercial property on city center is formed.

(2) Reconstruct the vertical section of line: this measure can improve the running speed and further improve the transport capacity of line, but it will be affected by engineering economy.

(3) Use new vehicles: new vehicles, including vehicle performance improvement and installation of vehicle control equipment, can shorten the interval time of train.

(4) Add train formation: with the permit of the station length, increasing the train formation can greatly improve the capacity of each train and effectively alleviate the bottleneck of line.

(5) Use advanced train operation control system: equipped with automatic train control system (ATC), the rail transit lines which display with a protective section of automatic blocking signal and centralized control can alleviate the bottleneck of transport capacity to a large extent.

(6) Divide the track circuit of station: Figure 1 (A) is the diagram of this measure to shorten time interval between trains spaced by automatic block signals. By dividing the track circuit of station area, the speed supervision grade is increased when a former train departures. When all the former trains have already gone across the circuit section of cd and reached the supervision speed, the latter trains just run to the approach line of a, as shown in figure 1 (B); when all the former train have already gone across the whole track circuit area of station, the latter trains just run to the approach line of a1, as shown in figure 1 (B). This measure can shorten the running time of the arrival of tracking trains.

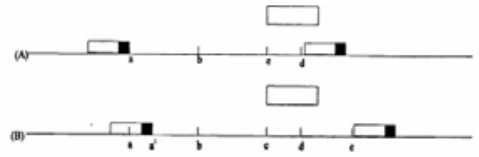

Figure1. Diagram of splitting track circuit

Optimize the layout of the reverse line of train: the optimization of the train reentry settings can greatly shorten reverse interval. As shown in figure 5-2, the terminal station is arranged in a double-island platform with a ring-back approach to increase the reverse line without reversing movement of train and shorten the boarding time. As shown in figure 5.2, the intermediate station is arranged in three-wire Twin Island, short routing train can reverse in front of the station and access to the middle line. When the train stops, opening the door on both sides can shorten the dwell time. The long routing train can be docked on both lines of the platform.

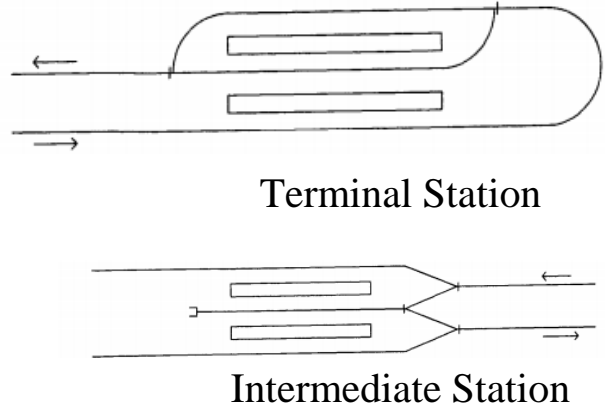

Figure2 Optimize layout of turning-back line

Change the way of reverse: when the reverse line is arranged, changing the way of reverse can also shorten the interval of reverse. For example, when the reverse line is pre-station crossing crossover, the alternative reverse is adopted. When the reverse line is post-station main line, the way of entering from sides and going out straight is used. In figure 3, the pre-station crossing crossover is adopted. The pre-station extension of the main line is the reverse line. In the way of going into from sides and going out straight, the receiving route of follow-up trains cannot be finished when former trains does not vacate the end of the reverse line of rail I. And when the trains enter from sides and go out straight from rail II, the receiving route of follow-up trains can be finished. Compared with these two kinds of 
reverse way above, we can see that the use of entering form sides and going out straight is more conducive to shorten the interval of reverse.

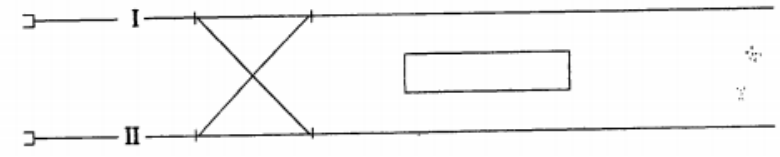

Figure3 Diagram of turn-back after station

Add side line: this measure which is generally applicable to the ground line can turn the side platform into an island platform. As shown in figure 4, one-way train can stop on both sides of the platform in turn so that to shorten the stay time of train in station and greatly improve the transport capacity of the bottleneck.

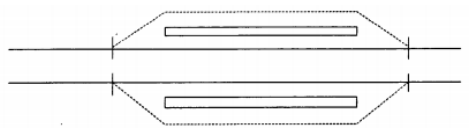

Figure4 Diagram of line adding lateral-line

(7) Add the platform: it is usually used in island platform to provide platform on both sides of the stop train, and passengers can get off or separate from both sides. As shown in Figure 5, the additional side line $s$ and platforms make island platform integrated. Meanwhile, side lines can be built according to the specific needs of the passenger flow.

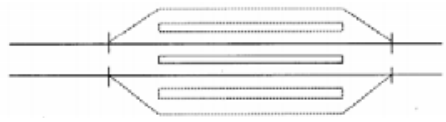

Figure5 Diagram of Island platform adding platform

\section{Selection of traffic organization solution}

In a certain range, the satisfaction of urban rail transit passenger is increased as the amount of investment. However, the passenger's satisfaction is not on the rise after a certain range, but the output investment ratio not increases as the investment allowance. When arriving at a certain amount of investment, although the passenger satisfaction is high, the urban rail transit cannot be fully used, which leads to the inadvisable waste of capability, as shown in figure 6 . Therefore, in the scheme selection, the passenger satisfaction and output / investment ratio shall be taken into account to determine the best reconstruction scheme.

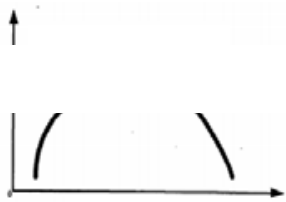

Figure6 The links of passenger satisfaction, output ratio and investment quantity

When there are more options in scheme selection, the most favorable scheme among them is the scheme that the sum of passenger satisfaction and ratio of output / investment is biggest, namely: In the formula of

$$
\left(\frac{U}{A}+P\right) \rightarrow \max
$$

$\mathrm{U}$-- output of the reconstruction A-- investment allowance of $\mathrm{P}$ in reconstruction-- passenger satisfaction

3. Determination of the optimal time for reconstruction

The optimal time for reconstruction shall be determined according to the character and the target of transport capacity. It is necessary to meet the long-term road network planning and passenger flow demand after the reconstruction to reach a long service period of the system. As we all know, with the aging and loss of urban rail transit facilities and equipment, the capacity of urban rail transit is reduced which cannot meet the growing demand for passenger flow. The year that the equipment is retrofitted to enhance the transport capacity (the year in which the transport capacity has been fully 
utilized) can be determined by using the transport capacity adaptation map. However, the period that transits from one measure to another cannot guarantee the most economic effect.

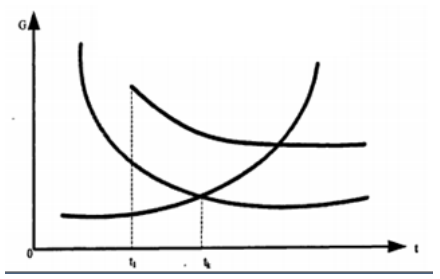

Figure7 Diagram of investment horizon

As shown in figure 7, it is an example of the transition from one measure to another of a certain urban rail transit line whose transition period can be specified in the year that the capacity has been maximized, and it is also possible to specify in the $t_{1}$ year that there is a surplus capacity. In $t_{1}$ years, investment in advance increases the investment spending of conversion. Namely: in the formula of

$$
A /(1+\Delta)^{4}>A /(1+\Delta)^{t_{k}}
$$

A-- the investment allowance of reconstruction measures $\triangle$ - effect coefficient of investment is equal to the reciprocal of the payback period.

However, in the years from $t_{1}$ to $t_{k}$ years, the enhancement of transport capacity brings the high satisfaction of urban rail transit passengers, more passengers and the benefits for the operation; that is to say, it increases $t_{1}$ to $t_{k}$ year conversion operating income. Namely, in the formula of

$$
\sum_{t=t+1}^{t_{1}} U_{t}^{1} /(1+\Delta)^{t}>\sum_{t=t+1}^{t_{t}} U_{t}^{0} /(1+\Delta)^{t}
$$

It refers to the operating income after $\mathrm{U}_{\mathrm{t}}{ }^{1}$ investment of the $\mathrm{t}$ years and the operating income after $\mathrm{U}_{\mathrm{t}}{ }^{0}$ investment of the $\mathrm{t}$ years. $\triangle$-- effect coefficient of investment;

Therefore, in the implementation of transformation measures, the most favorable time of reconstruction of $\mathrm{t} 1$ shall be determined, so that in the formula of

$$
E=\sum_{1}^{t_{1}} U_{t}^{0} /(1+\Delta)^{t}+\sum_{t_{1}+1}^{t_{t}} U_{t}^{1} /(1+\Delta)^{t}-A /(1+\Delta)^{t_{1}} \rightarrow \max
$$

It meets the above conditions of $\mathrm{t} 1$, the best time of reconstruction. In the context of the urban rail transit network, the study on the bottleneck of urban rail transit capacity is conductive to the rational allocation of resources and the transport organization optimization to give a full play to the transport capacity of urban rail transit system so that to achieve better social and economic benefits.

\section{References}

[1] Xiao Xuemei, Jia Limin. Reliability Evaluation Model for Urban Rail Transit Network Connection [J]. China Railway Science, 2016,01: 132-137.

[2] Li Xiaolong, Han Jingru, Song Liuyang. Study on calculation method of carrying capacity of urban rail transit network system [J]. Study of Urban Rail Transit Research, 2016,02: 71-75.

[3] Wang Zhipeng, Wu Yuanping. Identification Method of Urban Rail Transit Network Bottleneck [J] Journal of Chang'an University (Natural Science Edition), 2015, S1: 198-202.

[4] Shen Tuo, Pan Yixin, Deng Qi. Study on the Improvement of Traffic Capacity of Urban Rail Transit in Abnormal Conditions Based on Train Ranging [J]. Study on Urban Rail Transit, 2015,08: 111-115. 
[5] Wu Chaoqun, Pei Yulong, Gao Jingpeng. Analysis of Adjustment Capacity of Traffic Supply and Demand of Urban Rail Transit Network[J]. Journal of Wuhan University of Technology (Transportation Science and Engineering Edition), 2017,01: 22-26 + 31 . 